\title{
Instruir a los ángeles del hogar. La educación de las mujeres desde la perspectiva de dos periódicos locales: El Instructor y El Republicano, en la etapa porfiriana
}

\author{
To instruct the angels of home. The education of women from the perspective \\ of two local newspapers: El Instructor and El Republicano, in the porfirian era
}

\author{
Aurora Terán Fuentes*®
}

\begin{abstract}
Terán Fuentes, A. (2017). Instruir a los ángeles del hogar. La educación de las mujeres desde la perspectiva de dos periódicos locales: El Instructor y El Republicano, en la etapa porfiriana. Investigación y Ciencia de la Universidad Autónoma de Aguascalientes, 25(71), 77-84.
\end{abstract}

RESUMEN

En el siglo XIX la prensa de propaganda científica jugó un papel importante en la educación de las mujeres en el ámbito que se denomina como informal. Su provecho se justificaba por el reducido trayecto de educación formal de la mujer en Aguascalientes, porque básicamente recibía educación primaria y una minoría estudiaba la secundaria, máximo nivel al cual se podía aspirar. Por ende, la propaganda científica dedicada a la mujer tuvo la función social de transmitir y ayudar a la consolidación de una imagen centrada en la madre y esposa ilustrada que desde el hogar formaría ciudadanos y fomentaría el amor por el conocimiento científico. Se planteó como objetivo el análisis de dos periódicos locales del porfiriato: El Instructor trasmitía conocimiento al público femenino y El Republicano planteaba ante la opinión pública discusiones sobre la naturaleza de la mujer y su educación; fue un tema de relevancia para la opinión pública y de preocupación para la clase política, que derivó en política pública.

ABSTRACI

In the XIX century, the scientific propaganda press played an important role in women education, in an

Palabras clave: educación de la mujer; propaganda científica; prensa siglo XIX; porfiriato.

Keywords: women education; scientific propaganda; XIX century press; porfiriato.

Recibido: 19 de enero de 2017, aceptado: 6 de julio de 2017

* Universidad Pedagógica Nacional Unidad 011 Aguascalientes. Calle Jesús Consuelo 226, Colonia Gremial Ferrocarrilera, C. P. 20030, Aguascalientes, Aguascalientes, México. Correo electrónico: boristeranfuentes@yahoo.com.mx

$凶$

Autor para correspondencia informal way. Its benefit was justified by the limited path of formal education for women in Aguascalientes, because women only received elementary school education and in the minority of the cases, middle school education and that was the maximum any women could receive. Therefore, scientific propaganda dedicated to women had the social function of broadcasting and helping to consolidate the image of women as an illustrated mother and wife, who would form citizens and promote love through scientific knowledge. The suggested goal was to analyze two newspapers from the porfiriato era: El Instructor published knowledge for women audiences and El Republicano posed discussions about the nature of women and their education before the public opinion; this subject was relevant for the public opinion and an area of concern for the political class, turning into a public policy.

INTRODUCCIÓN

La prensa escrita en el siglo XIX significó un modo de educación informal para las mujeres al difundir conocimientos sobre valores cívicos y morales, temas científicos para aplicarlos en el hogar y transmitirlos a los hijos, así como asuntos propios del mundo femenino como la moda, corte y confección, recetas de cocina y reglas de etiqueta.

Para ilustrar lo anterior se mencionan tres medios nacionales de la época porfiriana destinados al público femenino: Álbum de Damas. Revista quincenal ilustrada, incluía secciones de labores manuales, jardinería y las biografías de mujeres ejemplares encarnadas en modelos a seguir como Carmelita Romero Rubio; El Álbum de la Mujer. Periódico ilustrado, incorporaba galerías de hombres y mujeres notables, y diversos escritos de cultura general sobre 
IIVESTIGACIÓn Y CIERCIA DE LA UNIVERSIDAD AUTÓNOMA

temas diversos como las vestales, catedrales, lugares como Pompeya, Florencia o El Cairo, entre otros, además de piezas literarias y reflexiones filosóficas; y finalmente El Diario del Hogar. Periódico de las familias, se encontraba en la línea editorial de propaganda científica y educación cívica, al incluir discursos sobre las fechas emblemáticas como el 15 de septiembre, cuestiones financieras o el conocimiento de actividades económicas, personajes célebres, temas de interés nacional como la inmigración y los ferrocarriles. En general el objetivo fue instruir a "los ángeles del hogar", un ideal de la filosofía ilustrada que concebía a las madres de familia como mujeres cultivadas, piezas fundamentales para formar a los futuros ciudadanos.

Desde lo local, El Republicano, fundado en 1867 por Jesús Gómez Portugal y duró 57 años, cuya dirección estuvo a cargo de: Agustín R. González, Antonio Cornejo, Blas Elizondo, Pablo de la Rosa, Macedonio Palomino, Rodrigo A. Espinosa y Jesús Bernal Sánchez; y El Instructor, fundado en 1884 por Jesús Díaz de León y publicado hasta 1907, fueron dos periódicos de Aguascalientes que proponían como contenido relevante de opinión pública la naturaleza y educación de la mujer, al publicar artículos sobre dichos tópicos y artículos de interés para las féminas (sobre todo en El Instructor) desde una visión masculina. En las notas periodísticas, claramente se presenta la mancuerna mujereducación.

A partir de la mirada de los dos periódicos locales, se observa el ideal de aquella época: la mujer en la trinchera de su hogar debía cumplir con su función social: educar a sus hijos, sería una persona que poseyera conocimientos científicos y una amplia cultura general y cívica, con el fin de sembrar en sus hijos el amor por la patria y por el conocimiento, para coadyuvar (comenzando por el ámbito privado) a llevar a la entidad en particular y el país en general al progreso y al bienestar, así como a la consolidación de la República y el orden liberal. En dicho ideal, la mujer debía ser un ejemplo de virtud. De este modo, algunos periódicos tuvieron como función social educar o instruir a la mujer.

El papel de la mujer en el siglo XIX se concibió medular, porque ella coadyuvaría a consolidar la patria y el proyecto de desarrollo de la nación. Cumpliría con un alto deber cívico: fomentar el amor al conocimiento y construir ciudadanía en sus hijos, bajo un modelo de virtud.
Una forma conveniente de instruir a la mujer fue a través de la prensa escrita, por medio de la propaganda científica, ésta fue la línea de algunos periódicos de la época. "Ante las limitaciones educativas que caracterizaron a las decimonónicas mexicanas, la prensa jugó un importante papel en cuanto difusor de conocimientos" (Alvarado, 2005, p. 19). Por ende, fue fundamental la instrucción de la mujer a través de la prensa.

El objetivo de investigación fue identificar elementos del discurso periodístico de la época, utilizados para construir el ideal, función social e importancia de la mujer y la importancia de su instrucción y educación (desde la perspectiva masculina) en la etapa porfiriana (finales del siglo XIX) en Aguascalientes, a través de los periódicos locales El Instructor y El Republicano.

Desde el enfoque de los estudios culturales que permiten trabajar imaginarios colectivos, discursos y representaciones sociales, las preguntas planteadas para el tema del discurso periodístico en relación con la naturaleza y educación de la mujer, fueron las siguientes: ¿cómo se concebía a la mujer hidrocálida a través del discurso de El Instructor y EI Republicano?, ¿̇cuáles fueron los temas dedicados a la mujer y por qué?, ¿̇por qué era imprescindible tratar el tema de su educación en la prensa escrita?

En la actualidad resulta importante realizar investigaciones históricas que estudien discursos, concepciones, roles, ideales construidos en diferentes espacios y tiempos sobre la mujer, para observar sin prejuicios desde el presente hacia el pasado, con el fin de enriquecer el debate contemporáneo en relación con el tema de la mujer (niñas, jóvenes y adultas), su educación e historia.

Algunos de los estudios publicados que abordan el tema de la prensa y la educación de la mujer son: "La educación de la mujer mexicana en la prensa femenina durante el porfiriato", de Torres Aguilar y Atilano Villegas (2015), donde se explica cómo la prensa fue una forma de educación informal para la mujer que presentaba dos visiones antagónicas; "una conservadora, que recomendaba educarlas, y otra liberal o modernizadora, que proponía instruirlas" (p. 218), y establece la diferencia que se explicaba en la prensa de la época: la educación estaba destinada al corazón, y la instrucción a la inteligencia. 
Ballarín, Birriel, Martínez y Ortiz (2010), en su libro Las mujeres y la historia de Europa plantean que en el siglo XIX fue indiscutible el derecho de las mujeres a la educación, porque el pensamiento de la llustración había aportado la igualdad de los individuos y la necesidad de construir pactos sociales; fue una época en que los gobiernos (europeos), veían como obligación garantizar escuelas para niñas, con un currículo diferenciado del de los hombres, para la reproducción de los roles tradicionales de la mujer relacionados con la virtud y el desempeño en el ámbito privado.

Staples (2015) expone que para ser una mujer ilustrada la condición era pertenecer a la clase acomodada y con un gusto desarrollado por la lectura, el teatro, la música y la pintura, además de ser partícipe en las tertulias; propone que en la medida en que transcurría el siglo XIX la opinión pública fue comulgando con la idea de ilustrar al espíritu (tanto para las mujeres como para los hombres), y destacaron las maestras y las escritoras. Alvarado (2005), estudia a Laureana Wright, una periodista que cuestionó los estereotipos y roles de la mujer a finales del siglo XIX, a través de la prensa escrita, un tema de debate fue el acceso de las féminas a la educación superior. Saloma Gutiérrez (2000) analiza los roles femeninos durante la época porfiriana, sintetizados en una visión dicotómica entre "lo biológico y lo cultural, lo privado y lo público, lo inferior necesariamente sujeto a lo superior; a la mujer correspondía la primera parte del binomio y al varón la segunda" (p. 3), el estereotipo fue "el eterno femenino y la debilidad de la mujer" (p. 3), y a partir de lo anterior comprender el modelo de familia de la segunda mitad del siglo XIX.

Finalmente, Infante Vargas (2008) analizó el tránsito de la lectura a la escritura que vivieron algunas mujeres, lo que permitió el surgimiento del rol de escritora, que transcendió el ámbito de la escritura en el espacio privado al público en el México decimonónico. Una fuente privilegiada en su estudio es el Diario de México, porque permite identificar géneros como el epistolar y la poesía, y temáticas como la moda, el teatro, "el enojo hacia la opinión de los varones sobre la pobreza del intelecto femenino; y el deseo de acceder a niveles de educación superior" (Infante Vargas, 2008, p. 78), que eran de interés para las mujeres.

\section{MATERIALES Y METODOS}

\section{El trabajo con periódicos amarillentos}

El método de trabajo desde la perspectiva de la Historia fue la consulta y la sistematización de información localizada en diversos acervos documentales, regularmente los archivos cuentan con hemeroteca histórica. Los periódicos son un tipo de fuente que permite reconstruir y analizar visiones de mundo, concepciones, tendencias, ideologías o sistemas de creencias y valores; es decir, los periódicos y revistas de la época transmitían una perspectiva de la realidad, que puede ser reconstruida con los recursos de la disciplina de la Historia.

A partir de la óptica metodológica de la Historia Cultural (Nueva Historia), concretamente se trabaja el discurso periodístico utilizando el enfoque del análisis del discurso y la teoría argumentativa, porque básicamente es de carácter retórico y persuasivo. Teniendo como conceptos base: imaginario y representaciones.

La fuente privilegiada de análisis son los periódicos El Instructor y El Republicano, sus ejemplares están resguardados y se pueden consultar en la sección de la Hemeroteca Histórica del Archivo Histórico del Estado de Aguascalientes. Se eligieron estos periódicos porque ambos reflejaban la línea oficial o de gobierno, por tanto, se observan el ideal de mujer y el concepto de educación femenina desde el discurso de la clase gobernante. No obstante, se recuperan otras fuentes que también muestran el discurso oficial, con el fin de identificar un metadiscurso sobre el tema en cuestión.

\section{Dos periódicos locales preocupados por el tema de la instrucción de "los ángeles de los hogares"}

Los dos periódicos con los que se trabajó planteaban información diferente con respecto al tema de la mujer y su educación. El Republicano, como un periódico oficial, publicaba leyes y reglamentos, no obstante, en algunos de sus espacios presentaba notas editoriales en las cuales se discutía la naturaleza de la mujer, así como el tema de la educación como un elemento o parte del motor del progreso, además se difundían discursos y diversa información sobre el Liceo de Niñas, escuela de Educación secundaria después convertido en la Escuela Normal de Aguascalientes, fundado en 1878 bajo el gobierno de Francisco G. Hornedo y que fue un proyecto de gran significado dentro de la política educativa local. 
IIVESTIGACIÓn Y CIERGIA DE LA UחIVERSIDAD AUTÓnOMH DE RGUASCALIERTES
Tanto el Liceo de Niñas como el Instituto Científico y Literario (dirigido a los varones) tenían la misma atención en espacios dedicados en ambos periódicos; no obstante, en el recurso destinado para cada plantel había una gran diferencia. Por ejemplo, en una nota de El Republicano del 11 de septiembre de 1881 se informaba sobre los egresos en materia de educación: 307.14 pesos se habían destinado al Instituto, 62.50 al Liceo y 166.66 a la instrucción primaria en general. Una explicación puede relacionarse con el tema de género, pero también con la diversificación del Instituto, porque de ahí se continuaría con estudios universitarios en diversas ramas del conocimiento; por otro lado, el Liceo era para preparar maestras.

La siguiente transcripción de un fragmento de una nota de El Republicano con fecha del 25 de enero de 1880 da cuenta de las visiones retrógradas y progresistas con respecto a la educación de la mujer en un periódico liberal que claramente manifestaba la pugna conservadores/liberales y cómo la balanza se inclinaba por la segunda visión:

La educación de la mujer ha sido cuestión que ha ocupado la atención de varios escritores, manifestando sus ideas según sus creencias. Si son hombres partidarios de antiguas doctrinas, oídlos criticar que las niñas aprendan clases que, según ellos, no son necesarias para su sexo; si son amantes del progreso y apóstoles de la libertad, vedlos aplaudir el método de enseñanza que hoy se sigue, y confesar que la mujer es capaz de aprender todo, y hasta llegar a hacer estudios tan superiores como los que hagan los hombres. (El Republicano, 25 de enero de 1880, p. 3)

En la cita precedente se observa el argumento del claroscuro, al presentarse dos posiciones antagónicas de forma maniquea con el fin de definir tendencias. A lo largo del discurso el argumento por excelencia para convencer y persuadir es el del progreso, entendido como avance para llegar a la cúspide de la civilización, la educación se entendía como un recurso para arribar al progreso, que traería bienestar a todos.

Por otro lado, en el periódico El Instructor (figura 1), como medio literario y científico, contenía secciones dedicadas a la mujer como: "Ciencia en el hogar", "Higiene" o "Miscelánea". En dichas secciones se buscaba que la mujer a través de la lectura aprendiera sobre una serie de fenómenos naturales, así como explicaciones científicas de situaciones vividas cotidianamente en el hogar como lo eran las enfermedades de los hijos o la alimentación. Para muestra basta un botón, se exponía en diversos números de El Instructor el tema de la alimentación de los recién nacidos, su importancia y la constitución de la leche materna. Otro ejemplo se encuentra en explicaciones sobre fenómenos meteorológicos, el aire, la atmósfera, el agua, la burbuja de jabón, las grasas minerales (vaselina, petrolina y neutralina), etc.; información presentada como objetiva, porque era científica. Al igual que en El Republicano, se publicaban noticias sobre el Liceo de Niñas.

Ambos medios impresos se deben contextualizar dentro de un discurso y políticas de nivel nacional que otorgaban un papel y función social central a la educación como una forma de asegurar la llegada al progreso (en este sentido era redundante el discurso), así como el reconocimiento de México ante un concierto de naciones civilizadas. En dicho sentido llama la atención la tendencia por fortalecer escuelas nacionales (Escuela de Medicina, Escuela de Ingenieros, Escuela de Bellas Artes, Escuela de Artes y Oficios, Conservatorio Nacional de Música, Escuelas Nacionales Primarias), algunas tanto para hombres como para mujeres; no obstante, era un modelo de carácter nacional concentrado en la Ciudad de México, en consecuencia, del interior de la República los que regularmente se desplazaban hacia la capital eran varones. Por ende, las señoritas no tenían una alternativa, a no ser la del Liceo de Niñas (para una minoría), que continuar con su ilustración en el ámbito de lo privado, de ahí se desprende una de las funciones de la prensa de carácter científico y literario.

Por ejemplo, El Republicano, en su carácter de periódico oficial, presentaba una visión eminentemente masculina de mundo; sin embargo, en su sección de avisos aplaudía las publicaciones dedicadas a la instrucción e ilustración de la mujer, como El Diario del Hogar. Además se transcribía la correspondencia particular del mismo, firmada por Laureana Wright, quien en una ocasión felicitó al gobierno local por impulsar al Liceo como un espacio en donde la mujer se educaría y con ello el hogar dejaría de ser un lugar oscurantista, deseando que la experiencia se replicara en otros estados del país; a continuación se transcriben algunas de las líneas publicadas por ella:

Felicitamos sinceramente a la hospitalaria capital de esta floreciente parte de la República por sus adelantos 


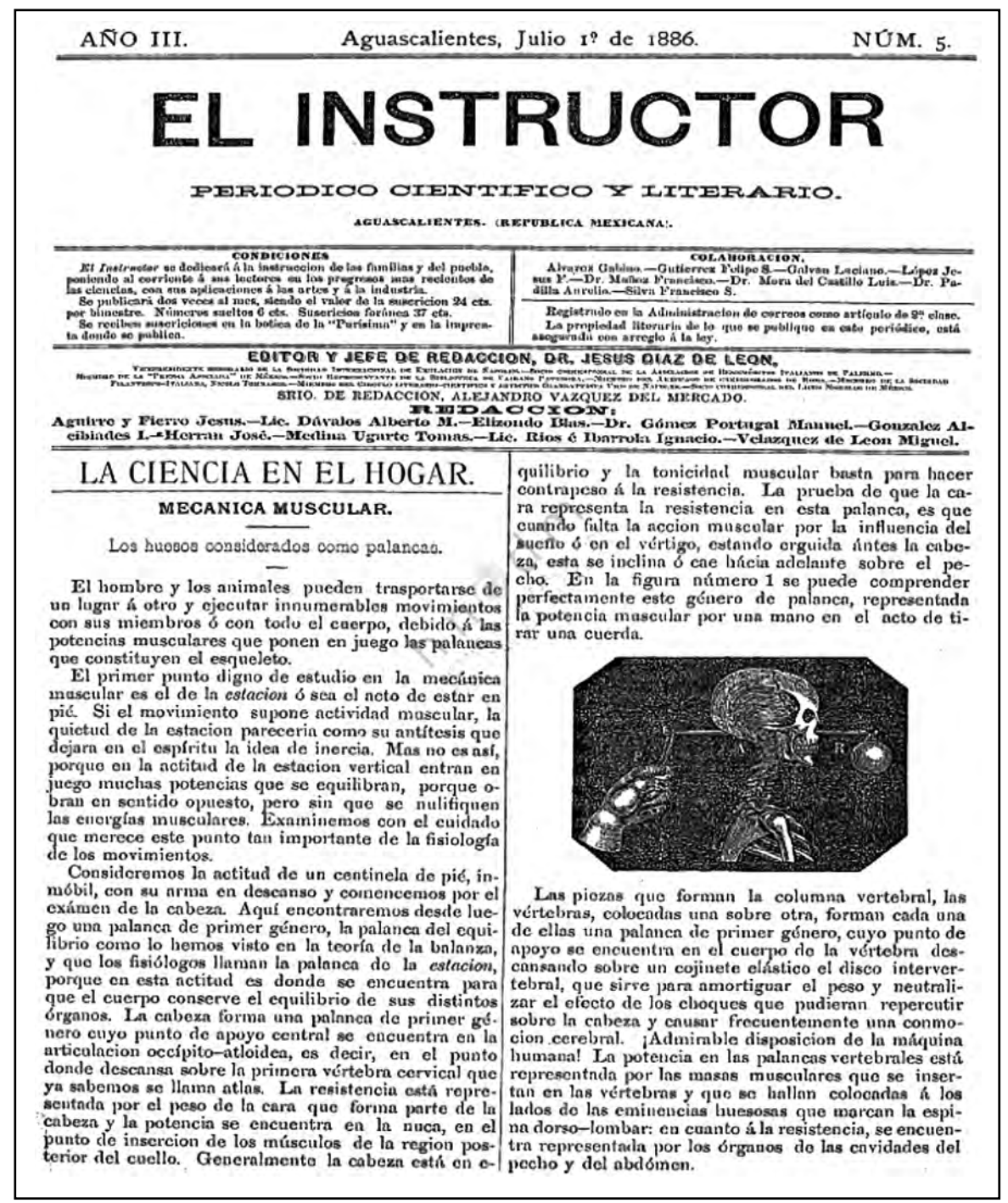

Figura 1. Periódico El Instructor, edición del $1^{\circ}$ de julio de 1886. Primera Plana. Sección "Ciencia en el hogar".

Se localiza y está en resguardo en el Archivo Histórico del Estado de Aguascalientes y en la Hemeroteca Nacional en la UNAM.

sociales, y nos regocijamos al contemplarlos, porque tenemos el pleno conocimiento de que la educación femenil, el encumbramiento de la mente de la mujer, hasta las eminentes alturas adonde ha llegado la del hombre, poniéndola a nivel de éste, es, y tiene que ser la base de la grandeza de las sociedades venideras. (Wright, nota publicada en El Republicano, 13 de enero de 1884, p. 4)

El argumento general era muy claro: instruir para caminar por la senda del progreso, en un siglo XIX en el cual México a nivel general y Aguascalientes en lo particular necesitaban del reconocimiento relacionado con un pueblo que transitaba a la civilización, fomentando las ciencias y las artes, al impulsar políticas y acciones en materia educativa.

\section{Otras fuentes oficiales}

A finales del siglo XIX se manifestó una tendencia relacionada con la celebración de congresos pedagógicos en diversas partes del mundo, en dichos encuentros se discutían temas relacionados con la higiene, el mobiliario de las escuelas, la educación positiva, la instrucción, las materias científicas y la educación de la mujer también se puso en la mesa de debates. En el presente trabajo se mencionan tres: dos que se llevaron a cabo en México y uno en Centroamérica.

En el Congreso Higiénico Pedagógico celebrado en 1882 se discutió el propósito de la instrucción primaria: que el hombre adquiriera los medios nece- 
IIVESTIGACIÓn Y CIERCIA DE LA UחIVERSIDAD AUTÓnOMH DE RGUASCALIERTES sarios para asegurar las condiciones de higiene para él y para su familia, traducidas en la alimentación, el vestido y la habitación; para lo anterior, el hombre tendría que trabajar y precisamente la escuela le proveería de los conocimientos necesarios "para poder formar y mantener una familia" (Memorias del Congreso, 1883, p. 144); es decir, se prepararía para ser el jefe del hogar, a la par de cumplir con los deberes de un buen ciudadano. Aunque no se menciona a las mujeres, es claro el discurso, el hombre se presenta como el jefe de la familia, para formar sus facultades físicas, intelectuales y morales, y cumplir con su función social, quedaba justificada plenamente su educación hasta el nivel superior, por ende, dicho nivel no era propio para las féminas. Se expone la importancia de la familia, la madre como la que cuida e inicia la educación de los hijos en el hogar y el padre como el proveedor que requería adquirir las destrezas para un trabajo que asegurara el bienestar del grupo familiar, por tal razón estudiaría más años que su compañera.

Con respecto al Segundo Congreso Nacional de Instrucción de 1891, cuando se aborda el tema de la mujer, se hace con relación a la educación normal, en su informe Justo Sierra, abogado, político, escritor y periodista de la segunda mitad del siglo $X I X$, que durante el gobierno de Porfirio Díaz fue subsecretario de Instrucción Pública a partir de 1901 y secretario de Instrucción Pública y Bellas Artes de 1905 a 1911, expuso como necesario un programa para las profesoras acorde con su papel y funciones sociales como mujeres, con el fin de no romper el equilibrio entre ambos sexos, ya que sus funciones eran claramente diferentes a las de los varones; exponía lo siguiente:

No es posible sostener, pese a la más sentimental y, en el fondo, a la más inhumana de las retóricas la paridad del hombre y la mujer ante la educación intelectual. Si tal cosa fuera cierta, ¿̇cómo podría conservar la mujer su inmensa superioridad sobre el hombre en la vida moral, en el mundo del afecto y el sacrificio? ¿Cómo podría desenvolverse en ella la aptitud divina que forma el íntimo encanto de nuestra existencia y que nos hace llevadero el peso de la vida (...). No; si a fuerza de extremar y alambicar el crecimiento intelectual de la mujer, atrofiamos en ella sus dotes congénitas, la vida perdería su precio y la civilización humana habría producido frutos de maldición. El día en que nos disputemos ellas y nosotros la palma de la sabiduría, habrá necesidad de inventar un mundo nuevo y de pedir al Dios del paraíso que nos diese otra Eva, que nos devolviese a nuestras esposas y a nuestras madres.
(Segundo Congreso Nacional de Instrucción. Informes y Resoluciones, 1891, pp. 69-70)

Más adelante, Justo Sierra defiende la idea de que lo importante para el Estado no son los grupos de personas, sino "asegurar elementos de conservación y mejoramiento social; el individuo no es su fin, sino la especie en su forma concreta de nación" (Segundo Congreso Nacional de Instrucción. Informes y Resoluciones, 1891, p. 70). Cada hombre y mujer tenían un cometido para consolidar a la República.

Es importante reconocer la igualdad y el derecho a la educación tanto de los hombres como de las mujeres, dicho postulado quedó manifiesto en las Memorias del Primer Congreso Pedagógico Centroamericano de 1893; "este Congreso ha aceptado ya, tácitamente, la igualdad sustancial en la educación del hombre y la mujer, al adoptar idénticos programas y métodos de enseñanza para las escuelas de uno y otro sexo" (p. 280), y después continúa con la siguiente sentencia: "reconocemos que en el pasado hemos sido poco justos con la mujer al no brindarle las mismas oportunidades que al hombre para mejorar su condición" (Primer Congreso Pedagógico Centroamericano de 1893, 1894, p. 280).

Acosta de Samper (2011) en su artículo "Aptitud de la mujer para ejercer todas las profesiones. Memoria presentada en el Congreso PedagógicoHispano-Lusitano-Americano reunido en Madrid en 1892" recupera los discursos y debates de dicho evento, que se inserta dentro de una tradición por celebrar congresos pedagógicos, porque la educación se concebía como un recurso indispensable para llegar al progreso; en este sentido, en los debates y exposiciones se planteaba la condición de la mujer y la necesidad de su educación porque no se podía mantener en un estado de ignorancia. También se discutió sobre la justa medida de dicha educación hacia las mujeres, es decir, ¿̇qué tanto educarla?, ¿hasta dónde?, dejarla sin educación, así como educarla hasta los niveles superiores implicaba riesgos que atentaban contra la moral y las buenas costumbres.

Por otro lado, así como a la mujer le correspondía la primera instrucción, ya sea como madre en el seno del hogar, o como maestra en la escuela de párvulos y de primeras letras, Baranda (1887), ministro de Justicia e Instrucción Pública de 1882 a 1901, nombrado por el presidente Manuel 


\section{IIVESTIGAGIÓn Y CUERCIA DE LA UกIVERSIDAD AUTÓOOOMA DE RGUASCHLIETTES}

González y ratificado por el presidente Porfirio Díaz, en su Memoria presentada al Congreso de la Unión con respecto al ramo de la instrucción pública, expresó que se debía "fundar una Escuela Normal para profesoras, porque no se le oculta que corresponde a la mujer propagar la primera instrucción, para lo cual se necesitan no sólo conocimientos en la pedagogía moderna, sino cariño, abnegación y ternura" (P. IX). Se esbozaba la necesidad de redoblar esfuerzos con respecto a la instrucción de los más pequeños, aunque estaba claro que el proceso civilizatorio requería cubrir hasta el nivel de educación superior. No obstante, claramente se menciona que quienes estudiasen en la Normal de Profesoras debían ser señoritas, en consecuencia, la mujer casada en su rol de madre y esposa estaría encargada desde el hogar de la educación de los hijos en sus primeros años de vida.

No se debe olvidar que el siglo XIX se caracterizó por un fuerte pragmatismo, por tal razón la mujer ocuparía su tiempo de una forma útil, por medio de la propaganda científica continuaría con su educación en la casa y utilizaría de una forma provechosa espacios dedicados a la lectura en el ámbito privado sin olvidar educar a sus hijos, atender a su esposo y cuidar su casa. La importancia de la educación queda sintetizada en las palabras de Baranda (1892):

La prosperidad de los pueblos, la firmeza de sus principios, la rectitud de sus costumbres, la pureza de sus sentimientos patrios, y en suma, el fundamento de la moral, dependen en gran parte de las ideas que unas generaciones trasmiten a las que les suceden, para continuar ese desenvolvimiento progresivo de la inteligencia, ese enlace de conocimientos que tanto importa a la vida de toda sociedad organizada. (p. XXII)

Todos los habitantes de México habrían de cumplir la función social que les correspondiera, la mujer: educar, ser un modelo de virtud y base moral del hogar.

CONCLUSIONES

Básicamente las mujeres que continuaban sus estudios se debían dedicar a la enseñanza, no obstante, también se les concibió en un ramo fundamental del proyecto moderno de nación que fue el de las comunicaciones, al formarlas también para ser telegrafistas.

En provincia eran pocas las alternativas, de ahí la importancia de la prensa como una forma de propaganda científica que instruía e ilustraba a la población, por tal razón se generaron espacios periodísticos destinados específicamente al público lector femenino, que (aunque no se cuente con datos), seguramente fue muy reducido.

El Republicano y El Instructor fueron medios impresos locales con líneas editoriales relacionadas con el liberalismo y el positivismo; es decir, con el ideario y proyecto republicano por un lado y con la valorización del conocimiento científico con modelos de enseñanza positivista por el otro. La mujer, desde el ámbito de lo privado, comenzaría a echar las raíces con respecto a ambas tendencias: cívica y progreso, como una forma de fincar imágenes de mundo. 
- Acosta de Samper, S. (2011). Aptitud de la mujer para ejercer todas las profesiones. Memoria presentada en el Congreso Pedagógico Hispano-Lusitano-Americano reunido en Madrid en 1892. Revista de Estudios Sociales, 28, 169-175. Recuperado de http://132.248.9.34/hevila/ RevistadeestudiossocialesBogota/2011/no38/13.pdf

- Alvarado, L. (2005). Educación y superación femenina en el siglo XIX: dos ensayos de Laureana Wright. [Transcripción y estudio introductorio]. México, D. F.: UNAM.

- Archivo General de la Nación.

- Archivo Histórico del Estado de Aguascalientes.

- Ballarín, P., Birriel, M. M., Martínez, C., \& Ortiz, T. (2010). Las mujeres y la historia de Europa. Granada, España: Universidad de Granada-Omega Alfa Biblioteca libre. Recuperado de http://digibug.ugr.es/bitstream/10481/22237/1/las-mujeres-yla-historia-de-europa.pdf

- Baranda, J. (1887). Memoria presentada al Congreso de la Unión. México: Imprenta del Gobierno.

$\bullet$

(1892). Memoria de Justicia presentada al Congreso de la Unión. México: Imprenta del Gobierno Federal.

- El Instructor (s. f). Periódico científico, literario y de avisos. Jesús Díaz de León (Editor). Aguascalientes, México.

- El Instructor ( $1^{\circ}$ de julio de 1886). [Imagen de primera plana]. México: Archivo Histórico del Estado de AguascalientesHemeroteca Nacional UNAM.
- El Republicano (s. f.). Periódico Oficial del Gobierno del Estado. Aguascalientes, México: Secretaría de Gobierno.

- Hemeroteca Nacional Digital de México (s. f.). UNAM.

- Infante Vargas, L. (2008). De la escritura personal a la redacción de revistas femeninas. Mujeres y cultura escrita en México durante el siglo XIX. Relaciones. Estudios de historia y sociedad, 29(113), 69-105.

- Memorias del Primer Congreso Higiénico-Pedagógico reunido en la Ciudad de México en el año de 1882. (1883). México: Imprenta del Gobierno.

- Primer Congreso Pedagógico Centroamericano de 1893. (1894). Guatemala: Tipografía y Encuadernación Nacional.

- Saloma Gutiérrez, A. (2000). De la mujer ideal a la mujer real. Las contradicciones del estereotipo femenino en el siglo XIX. Cuicuilco, 7(18), 1-18. Recuperado de http://www.redalyc. org/articulo.oa?id=35101813

- Segundo Congreso Nacional de Instrucción. Informes y Resoluciones. (1891). México: Imprenta de Francisco Díaz de León.

- Staples, A. (2015). Mujeres ilustradas mexicanas, siglo XIX. En Historia de las mujeres en México (pp. 137-156). México: Instituto Nacional de Estudios Históricos de las Revoluciones de México-Secretaría de Educación Pública.

- Torres Aguilar, M., \& Atilano Villegas, R. Y. (2015). La educación de la mujer mexicana en la prensa femenina durante el porfiriato. Revista Historia de la Educación Latinoamericana, $17(24), 217-242$. 